\title{
Diabetes registry overdue, if not obsolete
}

$\mathrm{S}$ o much, it seems, for a "fresh start." As much as a \$46-million diabetes registry was to have augured a new era of chronic disease management within Ontario, proponents also hoped it would restore the tarnished lustre of those responsible for steering the province into the world of e-health marvels.

But critics say the overdue registry has been beset by procurement miscues, surpassed by technological change and may already be worthy of being ditched as yet another example of a centralized approach to e-health run amok and having little clinical merit.

Advocates had billed the diabetes registry as one of the province's ehealth clinical priorities, along with improved management of medications and wait times (www.mississaugahalton lhin.on.ca/uploadedFiles/Home_Page /Integrated_Health_Service_Plan/Ontario \%20eHealthStrategy\%202009-2012.pdf). It was to have substantially aided in the treatment of the one million Ontarians with diabetes, while serving as the launch pad for eHealth Ontario's proposed \$150-million Chronic Disease Management System, under which the province also proposes to oversee patients with congestive heart failure, asthma and chronic obstructive pulmonary disease.

The registry was hastily launched in 2009 in the wake of a series of developments, including the firing of the CEO and the dismantling of the Smart Systems for Health Agency (eHealth Ontario's predecessor), as well as a provincial audit that took officials to task for developing such grandiose, technically complex follies as a seldomused \$800-million data transmission system that costs $\$ 72$ million annually to operate and the $\$ 80$ million Ontario Laboratory Information System (OLIS) that costs $\$ 15$-million annually to operate but has yet to be connected to clinics and now requires massive upgrades. The audit, which led to the resignation of former health minister David Caplan,

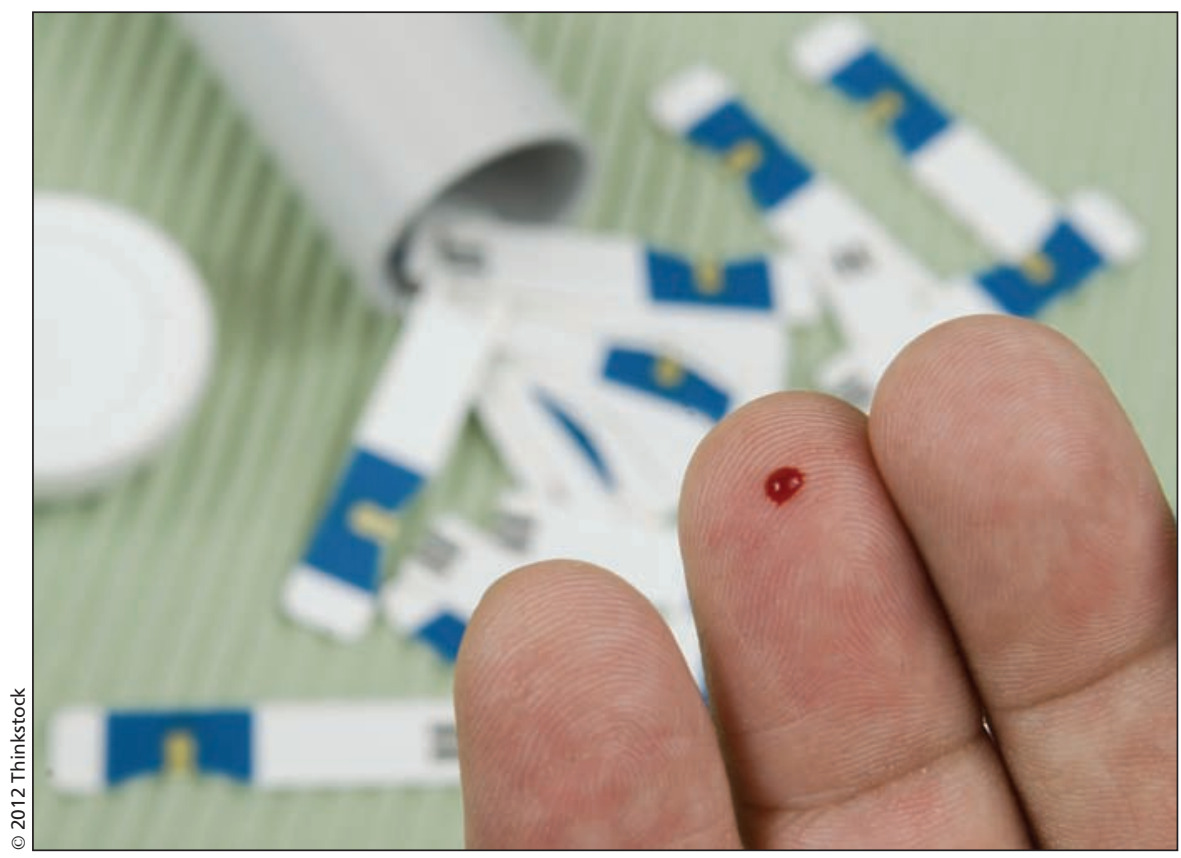

The diabetes registry was to have substantially aided in the treatment of the one million Ontarians with diabetes, while serving as the launch pad for eHealth Ontario's proposed \$150-million Chronic Disease Management System.

indicated that the agency had squandered $\$ 1$ billion over 10 years with a flurry of sole-sourced contracts and padded expense claims by well-paid consultants (www.auditor.on.ca/en /reports_en/ehealth_en.pdf).

Official planning for the registry had long since begun and when eHealth Ontario was created from the ashes of the spending scandal in 2009, the diabetes project was swept up in the tide of rebirth, although the Ontario College of Family Physicians warned that physician "uptake, regardless of incentives, will be limited" if it was developed on a stand-alone basis (www.ocfp.on.ca /docs/publications/e-health-and-family -medicine.pdf?sfvrsn=2).

The architecture for the registry was purchased off-the-shelf from Scotland by the winning contractor, CGI Information Systems and Management Consultants Inc., a subsidiary of Montréal, Quebec-based software giant CGI Group Inc. (www.infrastructure ontario.ca/What-We-Do/Projects/Project -Profiles/eHealth-Diabetes-Registry/).
It was to be fully operational in late 2011 and would, proclaimed eHealth Ontario CEO Greg Reed, "save lives, limbs and vision."

The province insists the registry is nearly operational but the problem is, there is no sign of it in hospitals and the clinicians who've been given a glimpse say they are sworn to secrecy.

That's because "the clinicians involved in the user acceptance testing of the Diabetes Registry have nondisclosure clauses as part of their service contracts," Robert Mitchell, vicepresident of stakeholder relations and communication for eHealth Ontario, explains in an email. "This is standard practice throughout the IT [information technology] industry, as the information they are privy to is propriety to the vendor and if shared externally, may unfairly advantage a competitor."

Insofar as insiders at either eHealth Ontario or within hospital networks will talk about the mysterious initiative, they'll only do so anonymously and are saying that plugging the Scottish sys- 
tem into Ontario's complex patchwork of hospital and physician electronic records is proving problematic.

Critics say the initiative is being plagued by the same sort of megaproject mania that seems to have undermined all manner of Canadian e-health initiatives, in which a fondness for massive, eyecatching health information systems becomes all-consuming (www.cmaj.ca /lookup/doi/10.1503/cmaj.109-4004).

"Even after all the big-system failures of the past they still have not learned to start developing e-health systems within health clinics first, see what works, and build them out," says Dominic Covvey, president of the Waterloo, Ontario-based National Institutes of Health Informatics. "The fundamental construct with massive systems such as the disease registry is wrong."

"There is even some question that systems like this may cause harm," notes Dr. David Chan, associate professor and director of information technology with the Department of Family Medicine at McMaster University in Hamilton, Ontario and developer of the electronic medical record system known as OSCAR. "Spending hundreds of millions of dollars on another centralized registry is very questionable. The money should be put where it counts, which is at the patient's bedside."

Dale Anderson, senior e-health consultant for the Hamilton Niagara Haldimand Brant Local Health Integration Network in Hamilton also questions the value of a province-wide registry for chronic diseases. "Almost all patient care is managed locally or regionally. ... Do you need a full-blown provincial system to do it? Maybe not."
Anderson adds that technological advances that allow for cloud computing and greater computer integration or what he calls "googlizing" — are rendering central data repositories obsolete. Diabetes data could be imported into existing systems, such as the $\$ 60$ million electronic children's health network, at little additional expense, he argues. "Our philosophy is to let hospitals manage the data. We concentrate on connecting them without committing huge dollars to huge projects."

William Falk, fellow in residence at the Mowat Centre for Policy Innovation at the University of Toronto, argues that large centralized systems have outlived their utility. "The rate of change has increased and so we need more local control," Falk, a leading contributor to Canada's first national e-health master plan, writes in an email. "Diabetes is an example in that the iPad didn't exist when the project was initiated and smartphones were in their infancy. The long cycle times make mega-projects ineffective."

Physicians who were recruited to test drive a "limited release prototype" of the diabetes registry say they've been told by officials that the initiative is on hold. "We were all asked to be credentialed on the registry," explains Dr. Jim MacLean, a family physician in London, Ontario. But according to hospital officials, says MacLean, "eHealth has put a stop on things for now."

"It's hard to say if it is being implemented," notes Dr. David Dixon, a London physician who serves on eHealth Ontario's physician council and who was also recruited to test the registry. "It may even turn out to be another OLIS."
Others identify a lack of consultation as having been a problem and suggest that more physician buy-in will be required if the registry is to have any value. "They recently contacted us about it but we haven't met them yet," says Darren Larsen, senior peer leader at Ontario MD, which is overseeing the installation of a $\$ 236$ million electronic medical record (EMR) system for 11 000 physicians. The diabetes registry will never be used unless it is compatible with physician EMRs, he warns. "Anything they build that is outside the EMR will not be used much." But until four months ago, the registry team "had never seen an EMR. That surprises me."

Mitchell indicated that the registry is still being tested and added in his email that the delay in implementation has had "no clinical impacts."

Mitchell referred inquiries about the causes of the delay to CGI, which declined comment, while Infrastructure Ontario, which is managing the contract on behalf of eHealth Ontario, indicates CGI won't be paid until it demonstrates that the system works.

Infrastructure Ontario also claimed that a "value for money assessment" from the professional services firm Deloitte \& Touche LLP which endorsed the government's decision to pay an additional \$6-million to CGI to develop the project using a privatized funding, operating and ownership model (www infrastructureontario.ca/WorkArea/Down loadAsset.aspx?id=2147485104), was justified despite the firm's failure to deliver the system on time. - Paul Christopher Webster, Toronto, Ont.

CMAJ 2012. DOI:10.1503/cmaj.109-4192 